\title{
Mitigating Lung Infections in Poor HIV Patients
}

\author{
Article by Lois Collie-Acasio \\ Ph.D. Clinical Research Texila American University \\ Email: licollie@yahoo.com
}

\begin{abstract}
Critical Appraisal of head-to-head studies is an important decision-making skill. Questions followed by evidence statements are responses that give researchers the evidence-based information they need to make decisions on the best treatment for an indication. The lung is the organ that HIV most frequently infects, and respiratory complications, such as pneumonia, are a common cause of death. The question of interest is: "Which of two treatments is the best one to mitigate lung infections in poor HIV patients?" This paper is a critical appraisal done to find an antibiotic that may be best for poverty-stricken HIV patients with pneumonia. There have been many reports of substandard drugs being donated to poorer countries. Critical appraisals need to be done on certain drugs that are donated to poverty-stricken countries to see if the drug is cost-effective, useful and affordable. It should be unethical to donate useless drugs to vulnerable poor HIV patients with lung infections.
\end{abstract}

Keywords: Critical appraisal, Decision-making, Randomized Controlled Trial (RCT) Human Immunodeficiency Virus (HIV)

\section{Introduction}

There may be several reasons why patients in low-income countries are not able to access the lifesaving drugs that they need.

1. The cost of the best intervention may be prohibitive.

2. The drug may need to be refrigerated, but refrigerators may not be accessible in rural areas.

3. The research, development, and production of the needed drug may not be profitable.

4. A substandard or counterfeit version of the needed drug may be available.

5. Foundations may be donating expired version of the needed drug.

The first thing that needs to be done is to identify the drug that is best and then seek ways and means to bring the costs down and to make the drug available without compromising quality.

This article is a critical appraisal of a clinical trial report and has been prepared for Texila American University E-Conference Participation. It has been peer-reviewed by the student supervisor. All the evidence statements are based on the information provided in a paper by (Cordero, E., Bouza, E., Ruiz, I., Pachon, J., 2001). Cefepime versus cefotaxime for empirical treatment of bacterial pneumonia in HIV-infected patients: an open, randomized trial. The graph shows the number of daily deaths from respiratory infections and HIV/AIDs. Infectious diseases are poverty-related. (WHO, 2004):

\section{Background}

Clinical scenario: Bacterial pneumonia is a severe opportunistic infection of the respiratory tract that targets HIV-positive people about eight times more than HIV-negative people, regardless of high CD4 cell and a good response to treatment. Although the introduction of powerful antiretroviral combination therapy in the battle against HIV has caused the incidence of bacterial pneumonia to drop, bacterial pneumonia is still life threatening to patients and may be acquired as a nosocomial infection as well from the community Some of the bacteria that cause respiratory tract infections and recurrent pneumonia in HIV-positive patients are Streptococcus pneumoniae, Staphylococcus aureus, Pseudomonas aeruginosa, and Haemophilus influenza, with the first one listed being the most 
common. Bacterial pneumonia may cause death when the bacteria infection becomes systemic, and the CD 4 count falls below 100. HIV-positive people with a higher risk of getting bacterial pneumonia when their lifestyle embraces cofactors such as smoking, use of alcohol, cocaine, and intravenous drugs, and those who have cirrhosis of the liver. (Aviram Galit and Phillip M. Boiselle, 2004)

\section{Objective}

To identify the better antibiotic for these patients.

Is the question that this study addresses focused?

\section{YES}

Evidence Statement 1

The question was clearly focused and addressed patients, intervention, comparing interventions and the outcomes (PICO): The participants in the study had bacterial pneumonia and were HIV- positive. The study compared the efficacy and safety of cefepime to cefotaxime (with dosage adjustments for Pseudomonas aeruginosa pneumonia) in the empirical treatment of bacterial pneumonia in HIVinfected patients. The primary endpoint concerned the safety and efficacy of both treatments with the clinical control of the bacterial infection as the secondary endpoint.

1. Was randomization and control used in assigning the subjects to the study drugs?

YES

Evidence Statement 2

The study was appropriately randomized and controlled. The randomization process was computerized, and the randomization list was concealed. It was a multi-centred study that involved a comparison of two antibiotic study drugs, and it was randomized to prevent participants and research staff from having the bias of favoring one drug over the other.

2. Were subjects allocated in a balanced and appropriate way to both arms of the intervention?

YES

Evidence Statement 3

The study had two well-balanced arms was comprised of hospitalized patients whom all had bacterial pneumonia and HIV infection.

3. Were the researchers and subjects 'blind' to the study group assignments?

NO

Evidence Statement 4

The study was open and not blinded. It was conducted in full compliance with GCP Guidelines and the Declaration of Helsinki.

4. Were all of the participants accounted for at the end of the study?

YES

Evidence Statement 5

All the participants were hospitalized and were analyzed either on an as per protocol (PP) basis or on an intention to treat (ITT) analysis in the groups to which they were randomized. In the ITT group, any participant that was not able to complete study was still regarded as a part of the study in the final analysis.

5. Was the method of follow up and data collection the same for all the groups?

YES

Evidence Statement 6

Follow-up was only done if it was clinically necessary. There usually was no need for a follow- up because the study lasted from 5 to of 7 days with one of the endpoints being if the participant found the study drug to be intolerable. The data was collected the same way in both arms of the study. (Cordero, E., Bouza, E., Ruiz, I., Pachon, J., 2001).

6. Were enough subjects enrolled in the study to minimize the possibility of chance? YES

Evidence Statement 7 
Statistical calculations were done to find out how many participants needed to be treated in order to give the right statistical power to the study. (Guyatt G.H, Sackett D.L, Cook D.J., 1993) The researchers assumed a success rate of $80 \%$ in the sample calculation. It was estimated that each treatment arm needed at least 76 participants in order detect differences that would be equal or greater than $15 \%$ with a 2 sided probability of alpha $=0.05$ and beta $=0.20$. A type 1 error (alpha) occurs when there is a probability that the null hypothesis has been rejected even though it was true and is taken to be equal or less than $5 \% \mathrm{p}<0.05$. A Type II error (beta) occurs when there is a probability that the null hypothesis is true when it is false, and this is taken to be equal to 0.20 when the power is from 80 to $90 \%$. The result of the power analysis revealed that the sample size of 150 and 160 per treatment arm was adequate to reveal any differences. As a result 76 subjects were recruited for the cefotaxime arm, 73 of which completed the study, and 84 subjects were recruited for the cefepime arm with 77 of them completing the study.

7. How were the results presented and expressed? What were the main results and the size of the treatment effect?

Evidence Statement 8

Data were presented in several tables that showed the main result was positive. The size of the treatment effect was significantly high, and the results were clearly expressed. The researchers used $\mathrm{x} 2$ tests and Fisher's exact tests to analyze the data and to make the comparisons. In order to determine factors that contributed to any failure of the treatment, the researchers used logistic regression analysis. From the calculations for Relative Risks and Relative Risks Reduction that follow in Tables 1, a, b, c, and d, it may be shown that no significant difference was observed in the way subjects tolerated both study drugs neither in the efficacy and clinical endpoints of both antibiotics.

\section{Results}

Table 1 a. Calculations

\begin{tabular}{|l|l|l|l|}
\hline As Per Protocol (PP) & \multicolumn{2}{|l|}{$\begin{array}{l}\text { Outcome event } \\
\text { Primary Endpoint: Tolerance } \\
\text { after 3-5 days }\end{array}$} & \\
\hline Group n=150 & Yes & No & Total \\
\hline Experimental group & a & b & a + b \\
\hline Cefepime 84 & $72(93.5 \%)$ & $5(6.5 \%)$ & 77 \\
\hline Control group & c & d & c + d \\
\hline Cefotaxime 76 & $59(80.8 \%)$ & $14(19.1 \%)$ & 73 \\
\hline
\end{tabular}

Experimental event rate $=$ risk of outcome event in experimental group $=$ EER $=\mathrm{a} /(\mathrm{a}+\mathrm{b})$

$=72 / 77$

$=0.93$

Control event rate $=$ risk of outcome event in control group $=$ CER $=c /(c+d)$

$=59 / 73$

$=0.80$

Relative risk $(\mathrm{RR})=\mathrm{EER} / \mathrm{CER}=0.93 / 0.80=1.16$ 
Texila International Journal of Clinical Research

Volume 3, Issue 2, Dec 2016

Table 1 b. Calculations

\begin{tabular}{|l|l|l|l|}
\hline Intention-to-treat (ITT) & \multicolumn{2}{|l|}{$\begin{array}{l}\text { Outcome event } \\
\text { Primary Endpoint: Tolerance }\end{array}$} & \\
& after 3-5 days & \\
\hline Group n=160 & Yes & No & Total \\
\hline Experimental group & a & b & a + b \\
Cefepime 84 & $72(85.7 \%)$ & $12(14.3 \%)$ & 84 \\
\hline Control group & $\mathrm{c}$ & $\mathrm{d}$ & $\mathrm{c}+\mathrm{d}$ \\
\hline Cefotaxime 76 & $59(77.6 \%)$ & $17(22.4 \%)$ & 76 \\
\hline
\end{tabular}

Experimental event rate $=$ risk of outcome event in experimental group $=$ EER $=a /(a+b)$

$=72 / 84$

$=0.857$

Control event rate $=$ risk of outcome event in control group $=\mathrm{CER}=\mathrm{c} /(\mathrm{c}+\mathrm{d})$

$=59 / 76$

$=0.77$

Relative risk $(\mathrm{RR})=\mathrm{EER} / \mathrm{CER}=0.857 / 0.77=1.11$

Table 1 c. Calculations

\begin{tabular}{|c|c|c|c|}
\hline As Per Protocol (PP) & \multicolumn{2}{|c|}{$\begin{array}{l}\text { Outcome event } \\
\text { Clinical Response to } \\
\text { antibiotics EOT }\end{array}$} & \\
\hline Group n=150 & Yes & No & Total \\
\hline $\begin{array}{l}\text { Experimental group } \\
\text { Cefepime } 84\end{array}$ & $\begin{array}{l}\text { a } \\
50(65.8 \%)\end{array}$ & $\begin{array}{l}\mathrm{b} \\
13(17.1 \%)\end{array}$ & $\begin{array}{l}a+b \\
63\end{array}$ \\
\hline Control group & C & $\mathrm{d}$ & $c+d$ \\
\hline Cefotaxime 76 & 50 (68.5\%) & $10(13.7 \%)$ & 60 \\
\hline
\end{tabular}

Experimental event rate $=$ risk of outcome event in the experimental group $=E E R=a /(a+b)$

$=50 / 63$

$=0.79$

Control event rate $=$ risk of outcome event in the control group $=\mathrm{CER}=\mathrm{c} /(\mathrm{c}+\mathrm{d})$

$=50 / 60$

$=0.83$

Relative risk $(\mathrm{RR})=\mathrm{EER} / \mathrm{CER}=0.79 / 0.83=1.25$

Relative risk reduction $(\mathrm{RRR})=(\mathrm{CER}-\mathrm{EER}) / \mathrm{CER}$

$(0.83-0.79) / 0.83=0.04 / 0.83$

$=0.04$ or $4 \%$

The bacterial infection may be reduced by $4 \%$ more in the treatment group than in the control group which is a comparatively small percentage of a difference between treatments.

Table $1 \mathrm{~d}$. Calculations

\begin{tabular}{|l|l|l|l|}
\hline Intention-to-treat (ITT) & \multicolumn{2}{|l|}{$\begin{array}{l}\text { Outcome event } \\
\text { Clinical Response to }\end{array}$} & \\
& antibiotics EOT & \\
\hline Group n=160 & Yes & No & Total \\
\hline Experimental group & a & b & a + b \\
\hline Cefepime 84 & $59(70.2 \%)$ & $14(16.7 \%)$ & 63 \\
\hline Control group & c & d & c + d \\
\hline Cefotaxime 76 & $59(77.6 \%)$ & $6(7.9 \%)$ & 65 \\
\hline
\end{tabular}


Experimental event rate $=$ risk of outcome event in the experimental group $=$ EER $=a /(a+b)$

$=59 / 63$

$=0.79$

Control event rate $=$ risk of outcome event in the control group $=\mathrm{CER}=\mathrm{c} /(\mathrm{c}+\mathrm{d})$

$=59 / 65$

$=0.91$

Relative risk $(\mathrm{RR})=\mathrm{EER} / \mathrm{CER}=0.93 / 0.91=1.02$

8. Were the results precise and presented with confidence intervals?

YES

Evidence Statement 9

Yes, CI data and p-values were presented on pages 429, 530 and 531 and the results were precise enough to show that both drugs were equally tolerated by the participants. This finding was supported by a similar study done with subjects that did not have HIV (Edelstein, H., Chirurgi, V., Oster, S., Karp, R., Cassano, K., Aiken, S., 1991). In the similar study of the effect that cephalosporin drugs have on bacterial pneumonia, the patients were not HIV compromised, and the study drugs were cefepime versus cefotaxime (NOT ceftazidime which has a similar name and is very similar in formulation and properties).

9. Were the important outcomes and results applicable to society?

YES

Evidence Statement 10

Yes. Although it did not reveal how many patients suffering from liver damage were in each arm of the study, all patients were given a creatine serum test, to check for liver damage. Exactly $64.3 \%$ of the participants had abused drugs, 56.2\% of them had a hepatobiliary disease, $18.7 \%$ abused alcohol and $81.8 \%$ were cigarette smokers. The dosages of medicines that are administered to HIV-positive patients should be calculated to go easy on their liver as it is highly probably that liver damage may be a co-morbid condition.

Many HIV Patients suffer from the end-stage of liver disease. Concerns about the high incidence of liver damage in HIV-positive patients have been expressed in several publications, and the administration of HAART drugs only makes the level of liver damage higher. Therefore, any drug intervention to an HIV patient must consider the additional damage that that drug may do the liver. (Crowe, David, 2011)

\section{Discussion}

\section{Summary of best evidence}

Table 2: Description and appraisal of Cefepime versus cefotaxime for empirical treatment of bacterial pneumonia in HIV-infected patients: an open, randomized trial, (Cordero, E., Bouza, E., Ruiz, I., Pachon, J., 2001)

\section{The objective of the study}

Study Design: The study was open and randomized by computer. The allocations were sealed, so the study was blinded. The outcomes measured how well patients tolerated the treatments, and how successful the antibiotics were in removing the bacterial infection.

Setting: This was a multi-centred and the subjects were hospitalized in eighteen (18) clinics in Spain.

\section{Participants}

Diagnosis: Bacterial pneumonia and HIV infected.

Inclusion criteria: participant must be 18 years old and above, male or female, must be HIV infected, with confirmed case of bacterial pneumonia, 
Texila International Journal of Clinical Research

Volume 3, Issue 2, Dec 2016

Exclusion criteria: allergic to cephalosporins, pregnancy, breastfeeding, previously enrolled in this study, a life expectancy of fewer than 60 days, or evidence of serum creatine of $2 \mathrm{mg} / \mathrm{dL}$ which shows severe liver damage.

The patient was recruited in emergency room settings, signed the informed consent form and then randomized on a 1:1 basis. The number of drop-outs did not affect the ITT or PP study and was minimal because the study lasted for no more than 7 days. Follow-up was done at the discretion of the clinician if needed.

Comparator Drug Arm: Cefotaxime. Assigned Drug Intervention: Cefotaxime $2 \mathrm{gm}$ IV tid

Comparator Drug Arm: Cefepime Assigned Drug Intervention: Cefepime $2 \mathrm{gm}$ IV bid $(2 \mathrm{~g}$ tid daily in case of Pseudomonas aeruginosa pneumonia)

\section{Intervention investigated}

To compare the tolerability and efficacy of cefepime versus cefotaxime: Open and blind multicentre study of hospitalized HIV-positive patients with HIV infection, $>18$ years of age with bacterial pneumonia. Patients were randomized to cefepime or cefotaxime 2 grams bid and tid respectively to be administered intravenously. Patients who responded could be switched to oral therapy.

Main Outcome Measures: Intolerance to the treatment and clinical success of the antibiotic therapy. Cefotaxime cleared the bacterial infection in 93.4\%, and Cefepime cleared it in $100 \%$ of the subjects. Patients had approximately the same amount of intolerance to both drugs.

\section{Critical appraisal}

\section{Validity}

Critical appraisal revealed that the clinical trial was properly conducted and that all the Critical points were properly addressed. All of the questions were answered positively.

The PEDro scales also did not find any fault with the design of the study. (PEDro, 1999)

\section{Area of Concern}

Enzyme induction is when drugs increase the liver enzymes and cause the rate of metabolism

to increase. Cigarette smoking, alcohol, and drug abuse may induce enzyme induction because of liver disease. These interactions are difficult to predict, and the patient may find it difficult to tolerate the study drug. Because of these concerns, the study has made tolerance of the drug its primary outcome.

\section{Interpretation of results}

The outcomes were favorable. The alpha level of probability was estimated to be $5 \%$ ( $\mathrm{p}$ - value $<0.05$ ), so it is statistically significant and not likely due to chance. CI scores were provided.

\section{Results}

Critical Appraisal of the meta-analysis provided evidence of the effectiveness of various forms of NRT smoking cessation interventions and justified their high cost. Critical Appraisal also showed that the two antibiotics in the head-to-head study, Cefepime, and Cefotaxime, were equivalent in effectiveness and tolerability. It was shown that the results of the both studies were valid and not due to chance. It has been shown that Cefepime antibiotics have the lowest average cost per patient. (Halpern, M., Brown, R., Drolet, M., Sorensen, S., Mandell, L., 1997)

\section{Conclusion}

Critical Appraisal identifies evidence-based interventions. Respiratory infections and HIV/AIDS are poverty-related communicable diseases with high mortality. (WHO, 2004) The risks of morbidity and mortality need to be reduced. Patients need to maintain an optimal QOL despite of opportunistic diseases. More critical appraisals are needed to identify safe, effective, and affordable interventions 
for poverty-stricken and unemployed patients. The economically disadvantaged HIV patients are vulnerable, and it should be unethical to give them watered-down HIV/AIDS drugs. Donations of such drugs need to be refused by the Public Health Departments of the countries concerned.

\section{Appendix: key formulas}

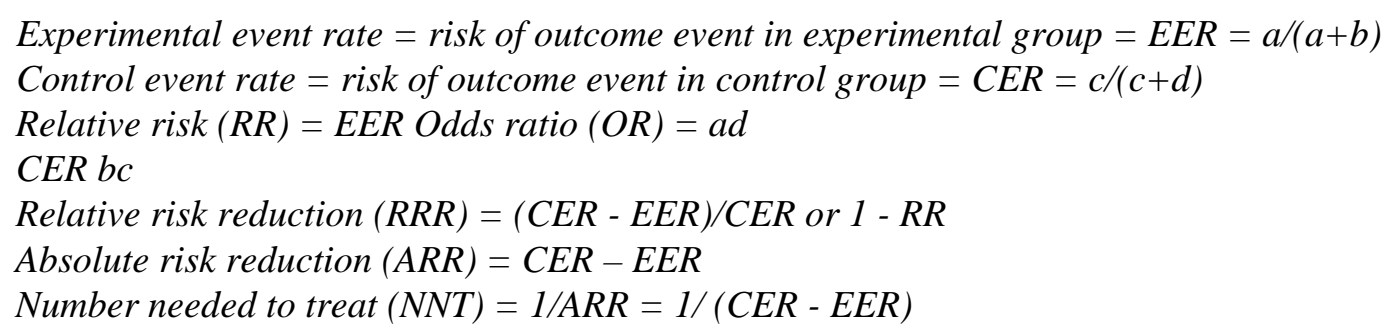

\section{References}

[1]. Aviram Galit and Phillip M. Boiselle (2004) Imaging Features of Bacterial Respiratory Infections in AIDS: Current Opinion Pulmonary Medicine, 10(3) [Online] Available at http://www.medscape.com/viewarticle/475231_2 (Accessed 15 September 2016)

[2]. Cordero, E., Bouza, E., Ruiz, I., Pachon, J. (2001). Cefepime versus cefotaxime for empirical treatment of bacterial pneumonia in HIV-infected patients: an open, randomized trial. J Antimicrob Chemother 48: 527-534 [Online] Available at http://jac.oxfordjournals.org/content/48/4/527 (Accessed 15 September, 2016)

[3]. CASP, (2006) Guyatt G H, Sackett D L, and Cook D J, Users' guides to the medical literature. II. How to use an article about therapy or prevention. Critical Appraisal Skills Programme, JAMA 1993; 270 (21): 25982601 and JAMA 1994; 271(1): 59-63 [Online] Available at http://www.sph.nhs.uk/sph-files/casp-appraisaltools/rct\%20appraisal\%20tool.pdf

[4]. (Accessed 15 September, 2016)

[5]. Crowe, David, (2011) Liver Damage, Concerns about HAART (Highly Active Anti-Retroviral Therapy), Alberta Reappraising AIDS Society [Online] Available at http://aras.ab.ca/haart-liver.html (Accessed 15 September, 2016)

[6]. Edelstein H, Chirurgi V, Oster S, Karp R, Cassano K, Aiken S, McCabe R(1991) A randomized trial of cefepime (BMY-28142) and ceftazidime for the treatment of pneumonia. J Antimicrob Chemotherapy,28(4):569-75.[Online] Available at

[7]. http://www.druglib.com/abstract/ed/edelstein-h_j-antimicrob-chemother_19911000.html (Accessed 15 September, 2016)

[8]. FDA, (2009) Maxipime (cefepime hydrochloride), Statistical Review and Evaluation, [Online] Available at

[9]. http://www.fda.gov/downloads/Drugs/DrugSafety/PostmarketDrugSafetyInformationforPatientsandProvid ers/DrugSafetyInformationforHeathcareProfessionals/UCM167309.pdf (Accessed 26 September, 2016)

[10]. Guyatt GH, Sackett D.L, Cook D.J., (1993) Users' guides to the medical literature. II.

[11]. How to use an article about therapy or prevention, A. Are the results of the study valid? JAMA 1993; (270): 2598-2601.,

[12]. [Online] Available at http://www.cche.net/text/usersguides/therapy.asp (Accessed 15 September, 2016)

[13]. Halpern, M., Brown, R., Drolet, M., Sorensen, S., Mandell, L., (1997) Decision analysis modelling of costs and outcomes following cefepime monotherapy in Canada, The Can J Infect Dis.1997 Jan-Feb; 8(1): 1927.[Online\} Available at http://www.ncbi.nlm.nih.gov/pmc/articles/PMC3327332/ (Accessed 16 September, 2016)

[14]. PEDro scale, (1999) Physiotherapy Evidence Data Base [Online] Available at http://www.pedro.org.au/english/downloads/pedro-scale/ (Accessed 15 September, 2016)

[15]. SIGN (2011) Methodology Checklist w: randomised controlled trials, Scottish intercollegiate guidelines Network, [Online] Available at http://www.sign.ac.uk/guidelines/fulltext/50/checklist2.html (Accessed 15 September, 2016) 
Texila International Journal of Clinical Research

Volume 3, Issue 2, Dec 2016

[16]. Silagy, C., Mant D, Fowler G, Lodge M., (1994) Meta-analysis on efficacy of nicotine replacement therapies in smoking cessation, The Lancet, 343, 8890 p. 139 [Online] Available at http://www.ncbi.nlm.nih.gov/pubmed/7904003 (Accessed 15 September, 2016)

[17]. SFAF, (2011) Syringe Access, San Francisco Aids Foundation, [Online] Available at http://www.sfaf.org/client-services/health-services/syringe-access/ (Accessed 15 September, 2016)

[18]. Mhaskar, R., Emmanuel, P., Mishra, S., Patel, S., Naik, E., and Kumar' A.,(2009) "Critical Appraisal Skills Are Essential to Informed Decision-Making." Indian Journal of Sexually Transmitted Diseases 30.2 (2009): 112-119. PMC. [Online] Available at http://www.ncbi.nlm.nih.gov/pmc/articles/PMC3168054/ (Accessed 15 Sept. 2016).

[19]. Oxman AD, (1994) CASP, User’s Guide to Medical Literature VI, JAMA 272:1367-1371

[20]. [Online] Available at http://www.ncbi.nlm.nih.gov/pubmed/7933399 (Accessed 15 September, 2016)

[21]. WHO (2004) Disease of poverty and the 10/90 Gap, World Health Organization [Online] Available at http://www.who.int/intellectualproperty/submissions/InternationalPolicyNetwork.pdf (Accessed 16 September, 2016)

[22]. Wu, P., (2006) Effectiveness of smoking cessation therapies: a systematic review and meta-analysis, Biomed Central Journal, 6:300 [Online] Available at http://www.biomed.com/1471-2458/6/300, (Accessed 15 September, 2016) 